\title{
DESIGN CENTRADO NA ATIVIDADE: ESTUDO SOBRE ARTEFATOS IMPRESSOS E DIGITAIS MÓVEIS
}

Turla Angela Alquete de Arreguy Baptista

Instituto Federal da Paraiba IFPB

Universidade Federal de Pernambuco - UFPE

turla.baptista@ifpb.edu.br

Silvio Romero Botelho Barreto Campello

Universidade Federal de Pernambuco - UFPE

sbcampello@gmail.com

Resumo: Este artigo apresenta os resultados de dissertação de mestrado sobre artefatos impressos e digitais móveis utilizados nas atividades de ensino e aprendizagem. Com objetivo de recomendar diretrizes para a análise e desenvolvimento de aplicativos educacionais que atendam às necessidades de aprendizagem dos alunos, esta pesquisa partiu de um experimento desenvolvido com sessenta alunos do ensino médio do Instituto Federal de Educação, Ciência e Tecnologia da Paraíba. Os sujeitos testaram materiais didáticos impressos e digitais e a partir dos dados do experimento procedeu-se uma análise comparativa entre os artefatos impressos e digitais. Esta análise teve como base metodológica a Teoria da Atividade de Leontiev (1978), o Sistema da Atividade de Engeström (1987), o estudo de Breakdowns e Mudanças de Foco de Bodker (1997). Com os resultados, foi possível discutir as principais diferenças entre o manuseio dos artefatos e a compreensão dos conteúdos educacionais. Ao final, esse estudo contribui com a elaboração de diretrizes para a análise e desenvolvimento de aplicativos educacionais para uso em tablet.

Palavras-chave: Aprendizagem Móvel, Teoria da Atividade, Interação Humano-Computador, Artefatos Impressos, Artefatos Digitais.

Abstract: This paper presents the dissertation results on printed artifacts and digital mobile artifacts used in teaching and learning activities. In order to recommend guidelines for development and analysis of educational applications that meet students' learning needs, this research came from an experiment developed with sixty high school students from the Federal Institute of Education, Science and Technology of Paraiba. The subjects tested print and digital learning materials and from the data of the experiment proceeded to a comparative analysis between the printed and digital artifacts. This analysis was based methodological Activity Theory Leontiev (1978), the System Activity Engeström (1987), the study of Breakdowns and Changes Focus Bødker (1997). With the results, it was 
possible to discuss the main differences between the handling of artifacts and understanding the educational content. In the end, this study contributes to the development of guidelines for the analysis and development of educational applications for use on tablet.

Keywords: Mobile Learning, Activity Theory, Human Computer Interaction, Printed Artifacts, Digital Artifacts.

\section{INTRODUÇÃO}

As tecnologias computacionais possuem hoje como um dos seus maiores expoentes os computadores em forma de prancheta, também chamados de tablets. Atributos como tecnologia touch screen, portabilidade e convergência fazem desse artefato uma ferramenta com aplicações variadas.

Embora seja uma tecnologia relativamente nova, há uma infinidade de aplicativos desenvolvidos para aprimorar a interação mediada por computador neste novo equipamento. Para este trabalho teremos como foco a análise da revista de conteúdo didático "Guia do Estudante", da editora Abril, em suas versões impressa e digital.

Os aplicativos educacionais desenvolvidos para tablet inauguram uma nova forma de interação, uma vez que a experiência de uso acontece com o toque dos dedos sobre a tela, permitindo um maior controle sobre a interface. No entanto, por ser um equipamento recente, ainda necessita de estudos que levem ao desenvolvimento adequado desses aplicativos, principalmente quando estes envolvem a internalização de conhecimentos para além do nível operacional.

Por outro lado, os materiais educacionais que utilizam o suporte impresso possuem diversos estudos voltados para a sua correta construção, tanto no que concerne aos aspectos formais, quanto aos aspectos que se relacionam com o conteúdo desenvolvido para esse tipo de artefato mediador da aprendizagem. No entanto, o uso de materiais educativos exclusivamente impressos já não é mais a realidade dos processos de ensino-aprendizagem. Cada vez mais os estudantes se apropriam das novas tecnologias e as utilizam como suporte aos materiais impressos, e por vezes, em total substituição destes pelos digitais.

Neste contexto, esta pesquisa teve como objetivo estudar a forma mais adequada de apresentar um conteúdo educacional em tablet, partindo da análise das atividades desenvolvidas ao longo do processo de uso de artefatos impressos e digitais. Esse trabalho não somente focará na análise da eficiência operacional, mas, sobretudo na eficiência para aprendizagem.

\section{APRENDIZAGEM MÓVEL}

O desenvolvimento do mobile learning (M-learning ou aprendizagem móvel) como uma recente estratégia da Educação a Distância só foi possível devido à incorporação da internet no cotidiano da vida em sociedade nos dias atuais. Com o advento de novas tecnologias móveis, o sistema educacional tradicional é, mais uma vez, colocado em xeque e convidado a repensar as suas ferramentas de ensinoaprendizagem em uso, incrementando-as com a incorporação dessas novas tecnologias. 
Por ser um campo de estudo ainda muito embrionário, não há consenso entre os teóricos sobre a definição mais adequada para o termo m-learning. Alguns o definem como uma modalidade de e-learning; outros colocam o foco sobre a tecnologia móvel; e muitos adotam a postura de buscar compreender a dimensão da mobilidade no processo de ensino-aprendizagem, no contexto de uma sociedade cada vez mais tecnológica. Reforçando esta última perspectiva, Batista $(2012$, p. 5) aponta que "para os autores, ao invés de assumir que a aprendizagem ocorre em um local fixo, como uma sala de aula, durante um período limitado de tempo, analisa-se como a aprendizagem flui por entre espaço, tempo e tecnologias".

Apesar da divergência de foco apresentada pelos estudiosos do tema, muitos concordam que não há mais como não enfrentar a questão da presença das tecnologias móveis no cotidiano da vida escolar. Assim, ao invés das proibições ou restrições ainda comuns em muitas unidades de ensino, especialmente no Brasil, cabe ao sistema educacional saber aproveitar essas novas ferramentas e redimensionar o papel do professor em sala de aula e, principalmente, otimizar o uso dessas novas tecnologias para melhorar a forma como os alunos aprendem os conteúdos educacionais.

Destaca-se ainda outro aspecto fundamental dentro do conceito de m-learning, que se traduz na atenção que é dada ao aluno no processo de ensino-aprendizagem. Por ser suportado em tecnologias móveis e pessoais, o m-learning é considerado uma modalidade de ensino centrada no aluno, quase personalizado, possível der ser efetivado por ser ubíquo e em rede, ou seja, a aprendizagem podendo acontecer em qualquer tempo e lugar.

Dando continuidade ao argumento, Traxler (2007) aponta que o conceito de aprendizagem móvel reflete uma nova concepção de sociedade; reflete novas formas de aprendizagem e, principalmente, de organização do conhecimento e como este pode se relacionar com o aluno: 'just-in-time,' 'just enough,' and 'just-for-me.' Como desdobramento, a produção do conteúdo também precisa ser repensada e adaptada as essas novas formas de se relacionar com a aprendizagem. Como afirmam Moura e Carvalho (2008, p.1), "essa mudança no paradigma pedagógico exige também mudanças na maneira como os materiais educacionais são projetados, desenvolvidos e disponibilizados para qualquer pessoa que queira aprender".

Com essa fundamentação foi que esse trabalho teve como foco a busca por diretrizes para a análise e desenvolvimento de aplicativos educacionais para uso em tablet.

\section{TEORIA DA ATIVIDADE DE LEONTIEV}

A Teoria da Atividade surge a partir de pesquisas realizadas por Lev Semenovitch Vygotsky, Alexander Luria e Alexei Leontiev. Da união entre esses três pesquisadores surgiu a "Tróica", um grupo que tinha como objetivo reconstruir a ciência psicológica sob a base do marxismo, formando assim a escola histórico-cultural Soviética nos idos de 1925.

Segundo Barreto Campello (2009, p. 191), "Vygotsky exerceu influência sobre a produção de Leontiev ao introduzir a noção de que toda ação humana é mediada, seja por ferramentas materiais, seja por ferramentas psicológicas, ou por ambas simultaneamente". Tal abordagem afirma ainda que as ações mediadas são direcionadas a um objetivo. 
Esta relação entre sujeito-objeto mediada por ferramentas tem como resultado a consciência, que na abordagem histórico-cultural não é apenas o resultado da evolução biológica, mas também da relação social e histórica entre indivíduos e destes com objetos.

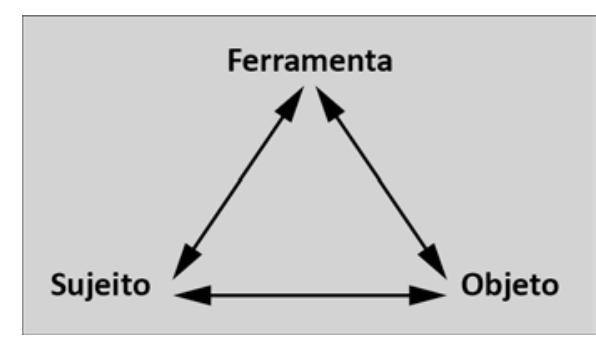

Figura 1 - Estrutura da atividade: tríade sujeito-ferramenta-objeto.

Fonte: Barreto Campello (2009)

A questão mais relevante é que "transmitir um meio ou método de realização de um ou outro processo é impossível, exceto numa forma externa - na forma de ações ou na forma de linguagem externa" (LEONTIEV, 1978, p. 59). Ao apresentar a consciência como parte de um contexto social e histórico, Leontiev reconhece que a dialética das relações entre sujeito e objeto, entre indivíduo e sociedade, é percebida a partir de sistemas sociais de atividades. Nestes sistemas há múltiplas mediações que estão inseridas nas atividades desempenhadas por indivíduos em um determinado contexto, em uma determinada comunidade.

Assim, os estudos de Leontiev inserem, como um princípio explanatório dos processos mentais, a noção de atividade social. Para o autor, atividade são "aqueles processos que, realizando as relações do homem com o mundo, satisfazem uma necessidade especial correspondente a ele" (LEONTIEV, 1978, 2004, 2012, p. 68; BARRETO CAMPELLO, 2009). Ainda sobre atividade, Leontiev $(2012$, p.68) a define da seguinte forma: "por atividade, designamos os processos psicologicamente caracterizados por aquilo a que o processo, como um todo, se dirige (seu objeto), coincidindo sempre com o objetivo que estimula o sujeito a executar esta atividade, isto é, o motivo.

Desta forma, a atividade é um processo de mediação entre sujeito e objeto e a estrutura desse processo é composta por três níveis interrelacionados: a atividade, as ações e as operações. A atividade é realizada por um conjunto de ações e as ações são realizadas por um conjunto de operações.

Para entender melhor como funciona a relação entre os níveis da atividade, segundo Moreira, Pedrosa e Pontelho (2011): "a estrutura da atividade, proposta por Leontiev (1978) pode então ser representada, na tabela 1, em três níveis que se articulam de forma dinâmica: o da atividade dirigida a um objeto que é o motivo da mesma; o das ações, processos subordinados por objetivos conscientes, que se relacionam ao motivo/objeto não individualmente, mas por meio de sua realização conjunta; o das operações, que expressam as condições humanas e instrumentais de realização das ações (p.19).". 
Tabela 1 - Estrutura e fator de orientação da atividade humana segundo Leontiev

\begin{tabular}{l|l} 
Nível & Fator de Orientação \\
\hline Atividade & Motivo \\
Ação & Meta \\
Operação & Circunstâncias
\end{tabular}

Fonte: Barreto Campello (2009)

Assim, tem-se que o fator de orientação da atividade é o motivo; o da ação é a meta; e o da operação são as circunstâncias. A relação entre os três níveis é mutável por natureza, uma vez que depende da relação dialética entre o sujeito/ferramenta/objeto desenvolvida ao longo da atividade social. Destarte, a teoria desenvolvida por Leontiev tem como foco a atividade que o indivíduo se engaja. De acordo com Barreto Campello (2009, p.193), "em atividade, o indivíduo se apodera das ferramentas psicológicas disponíveis e ulteriormente as internaliza". Desta forma, a atividade pela qual o indivíduo se engaja torna-se a unidade de análise, sendo possível observar mudanças no processo mental deste indivíduo durante a atividade praticada por ele.

Os estudos de Leontiev sobre a Teoria da Atividade foram absorvidos por uma diversa gama de autores e aplicados nas mais distintas áreas. A seguir será apresentada a contribuição feita por autores que se dedicaram à aplicação dos postulados de Leontiev no campo da 'atividade mediada por computador'.

\section{TEORIA DA ATIVIDADE APLICADA À ATIVIDADE MEDIADA POR COMPUTADOR}

Os primeiros trabalhos que integram a Teoria da Atividade ao campo da Interação Humano Computador (IHC) remontam o final da década de 80. Segundo Kapelinin e Nardi (2012), neste período, as aplicações da TA eram de duas naturezas: 1) empregada como modelo conceitual para balizar novas pesquisas em IHC; 2) utilizada para análise retrospectiva de projetos já desenvolvidos sobre IHC. Bodker (1989) foi pioneira na aplicação da primeira abordagem, bem como Kuuti (1991), Nardi (1992) e Kaptelinin (1992). Entre os que aplicaram a segunda abordagem estão Bodker (1991) e Nardi (1994). No Campo teórico da TA, Engeström (1987) apresentou avanços importantes ao desenvolver a noção de Sistema de Atividade. A contribuição deste autor será particularmente discutida no tópico a seguir.

Ainda sobre esse período, a título de exemplo, Bodker (1989) desenvolveu estudos na área de design de interface, que ressaltavam a importância de integrar o contexto sócio-cultural na elaboração de softwares. Para a autora, "um aplicativo de computador, da perspectiva do usuário, não é simplesmente algo que o usuário opera, mas algo que o usuário opera através de objetos ou assuntos de interesse na atividade de trabalho. Em outras palavras, os seres humanos operam através da aplicação informática, bem como de outras ferramentas, materiais que estão se transformando em produtos com a ajuda dos outros" (Bodker, 1989, p. 173).

Nas décadas seguintes, de acordo com Kapelinin e Nardi (2012), a aplicação da Teoria da Atividade, deixou de ser generalista e passou a atuar em áreas específicas de estudo, tais como o mobile learning (UDEN, 2007; KUUTT, 2010), affordance (ALBRECHTSEN ET AL. 2001; BAERENTSEN e TRETTVIK, 2002; KAPTELININ e NARDI, 
2012), usabilidade para aprendizagem (BARRETO CAMPELLO, 2003) ou serviços (KAPTELININ e UDEN, 2012).

\section{MÉTODO DE PESQUISA}

Para alcançar os objetivos apresentados nesta pesquisa, foram seguidos os seguintes passos metodológicos:

\subsection{Revisão Bibliográfica}

Nesta fase, foram selecionadas as principais contribuições teóricas para a área do Mobile Learning, Design de Interação e Teoria da Atividade, que se apresentam como a base teórica para este trabalho. Esta atividade teve como objetivo situar teoricamente a pesquisa, apontando divergências e aproximações com o estado da arte.

\subsection{Escolha dos Artefatos Educativos}

Esta etapa teve como objetivo escolher os artefatos que foram alvo de análise e do estudo experimental. Buscou-se por materiais de ensino médio que possuíssem conteúdos idênticos nas versões impressas e digitais, uma vez que o experimento teve o intuito de não só testar o artefato digital, mas também o seu modelo impresso. A testagem dos dois modelos fez-se necessária, pois a Teoria da Atividade analisa, entre outros elementos, o desenvolvimento histórico e social dos artefatos.

Para a pesquisa, o material didático escolhido foi a revista Guia do Estudante, da Editora Abril (Figura 01), pois possui as versões impressa - em formato de revista - e digital - desenvolvida para tablet.
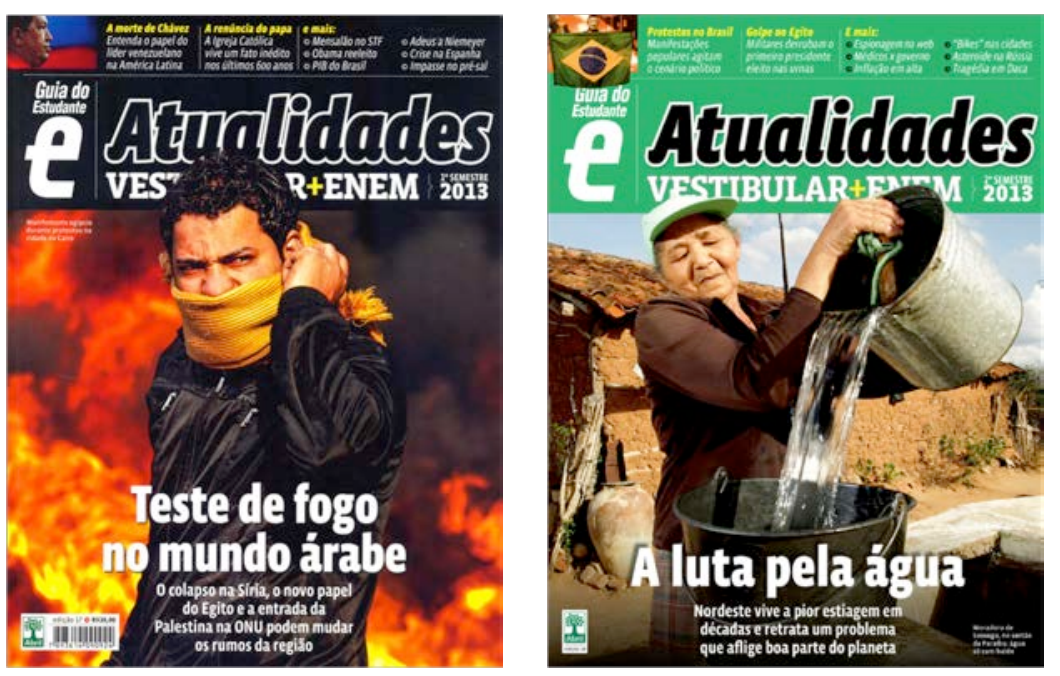

Figura 2 - Capas da Revista Guia do Estudante - Volume 1 e 2 .

Fonte: Editora Abril

Os conteúdos das revistas impressa e digital são exatamente iguais: capa, sumário, capítulo (Figuras 02 e 03), porém, na maioria dos casos, divergem na forma de apresentação das informações. 


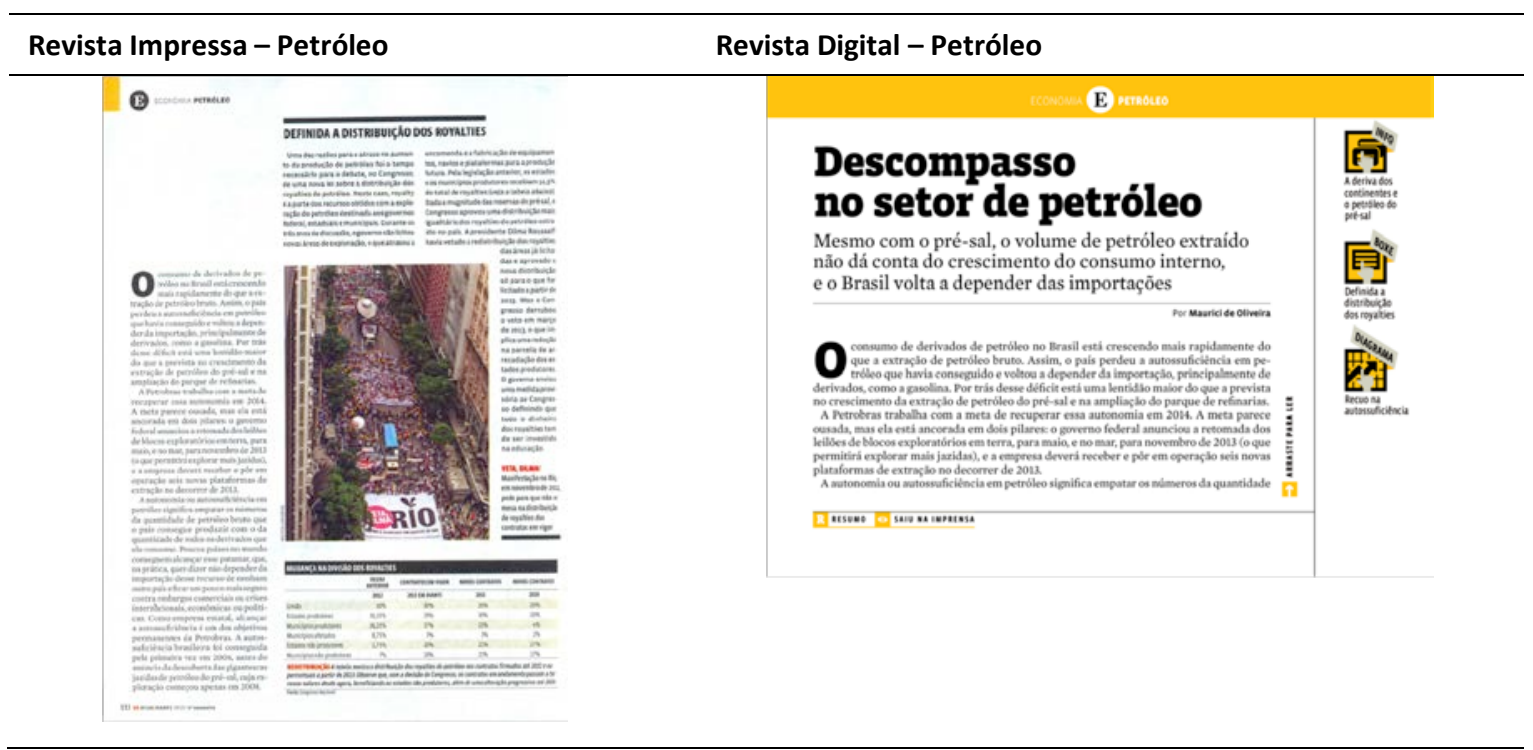

Figura 3 - Páginas de Conteúdo do Capítulo - revista impressa e digital (Capítulo Petróleo - Revista Guia do Estudante, Volume 01).

Fonte: Editora Abril

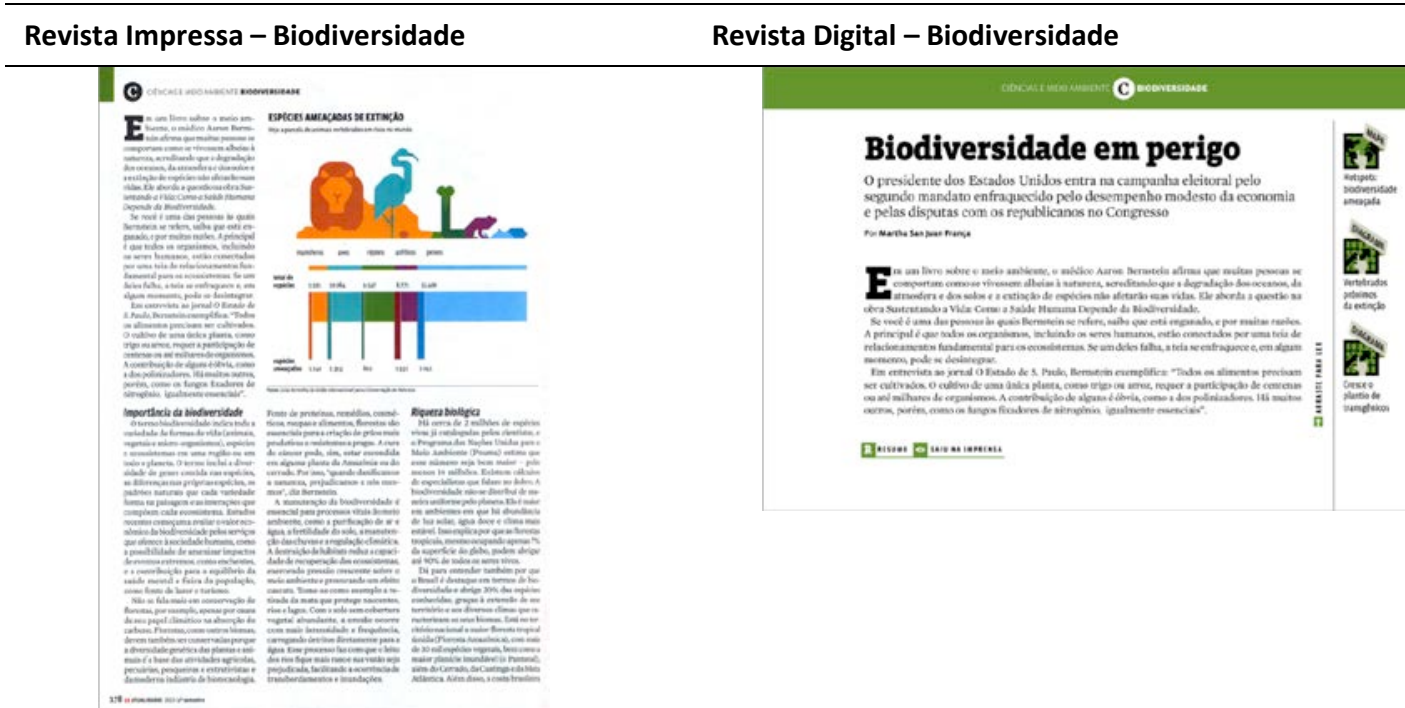

Figura 4 - Páginas de Conteúdo do Capítulo - revista impressa e digital (Capítulo Biodiversidade Revista Guia do Estudante, Volume 02).

Fonte: Editora Abril

Foram utilizados dois capítulos, que tiveram como requisitos para escolha: 1) A variedade de objetos de aprendizagem, como textos, imagens, infográficos, entre outros; 2) Texto com poucas páginas por se tratar de um experimento longo; 3) Tema de pouco conhecimento dos alunos, mas que pudesse despertar interesse para 0 aprendizado do conteúdo.

Ressalta-se que o objetivo desta pesquisa não foi analisar detalhadamente os aspectos estéticos e técnico formais dos elementos de composição da página. Buscouse apenas descrever estes elementos com o intuito de identificar as similitudes e divergências entre os artefatos impressos e digitais, contribuindo assim para a construção de instrumentos de análise da experiência dos alunos na atividade de leitura das revistas impressa e digital. 


\subsection{Definição dos sujeitos participantes da pesquisa}

Os sujeitos participantes do experimento são alunos do ensino médio do Instituto Federal de Educação, Ciência e Tecnologia da Paraíba. O experimento aconteceu no Campus Cabedelo devido à facilidade de acesso aos alunos de ensino médio, já que a pesquisadora possui vínculo com a instituição.

Optou-se por alunos do primeiro ano do ensino médio, pois o material didático referia-se ao conteúdo do Enem. Embora não tenha sido descartada a possibilidade dos alunos já conhecerem o conteúdo das Revistas, havia menores chances dos alunos dominarem os conteúdos que foram alvo do experimento, por eles serem do primeiro ano e, de modo geral, não terem contato com o conteúdo de todas as disciplinas abarcadas pelo Enem.

Ao todo participaram da pesquisa sessenta alunos, divididos em dez para o experimento piloto e cinquenta para o experimento final. Este quantitativo equivalia à aproximadamente $67 \%$ dos alunos do primeiro ano do ensino médio das turmas do 1 은 ano, no ano de 2014.

\subsection{Experimento}

O experimento foi de natureza quali-quantitiva e tem como objetivo analisar a atividade desenvolvida pelo aluno durante a leitura do material didático. 0 experimento dividiu-se em experimento piloto e experimento final.

Experimento Piloto - foi aplicado em dez alunos do ensino médio, que foram separados em dois grupos: A) grupo de cinco alunos que testou um artefato impresso; B) grupo de cinco alunos que testou um artefato digital.

O experimentos piloto possuiu três etapas:

1) Observação da leitura do conteúdo do artefato pelo aluno: teve como objetivo observar todas as ações e operações desenvolvidas pelo aluno durante a atividade de leitura de apenas um dos capítulos do material testado.

2) Avaliação de aprendizagem: visou avaliar a aprendizagem dos alunos em relação ao que foi lido, porém com foco em identificar os problemas do material e do conteúdo presente neste. A avaliação abarcou oito perguntas sobre o material lido anteriormente.

3) Entrevista semi-estruturada: com o objetivo de extrair informações sobre a atividade de leitura do artefato utilizado e questões referentes ao contexto de aprendizagem dos alunos.

A partir da experiência do piloto, foi possível identificar alguns quesitos que sofreram alteração para o experimento final, que serão explorados em seguida.

Experimento Final - foi aplicado em cinquenta alunos que se dividiram em dois grupos: 1) grupo de vinte e cinco alunos que testou um artefato impresso $A$ e artefato digital $B$; 2) grupo de vinte e cinco alunos que testou um artefato impresso $B$ e artefato digital A. O artefato A foi o capítulo sobre Petróleo da Revista Guia do Estudantes - 10 semestre de 2013. O artefato B foi o capítulo sobre Biodiversidade da Revista Guia do Estudantes - 2o semestre de 2013. O mesmo capítulo foi testado em seu formato impresso (revista impressa) e em seu formato digital (revista digital em formato de aplicativo para tablet)

O experimento final também se dividiu em três etapas:

1) Questionário: as perguntas do questionário foram elaboradas a partir dos resultados da entrevista semi-estruturada e dos demais dados obtidos no experimento 
piloto. As perguntas tiveram como objetivo extrair informações sobre a atividade de leitura do artefato utilizado, questões referentes ao contexto de aprendizagem e perfil dos alunos. $O$ questionário foi aplicado em quatro momentos do experimento.

2) Gravação em vídeo da leitura do conteúdo dos artefatos pelo aluno: cada aluno leu um capítulo no artefato impresso e outro capítulo no artefato digital. Os capítulos possuíam conteúdos diferentes. Com a troca de capítulos e artefatos entre os grupos foi possível analisar dois capítulos do conteúdo impresso e dois capítulos no conteúdo digital e ainda confrontar a experiência de um mesmo aluno com artefatos diferentes. Optou-se por analisar dois capítulos de conteúdos diferentes para reduzir o viés que poderia ocasionar a facilidade ou preferência que um aluno possa ter por uma matéria específica.

3) Avaliação de compreensão do conteúdo: teve como objetivo avaliar a compreensão dos alunos em relação ao conteúdo das revistas, porém com foco em identificar os problemas do material e do conteúdo presente neste. A avaliação continha oito perguntas sobre cada um dos capítulos que foram lidos pelos alunos. $O$ modelo de avaliação utilizado no piloto apresentou falhas no que diz respeito a mensurar o nível de performance dos alunos em relação ao conteúdo do material. $\mathrm{Na}$ tentativa de corrigir estas falhas optou-se por um novo método de avaliação que teve como base o modelo de análise de Spinillo e Hodges (2012).

\subsection{Análise dos Dados}

Esta etapa teve como objetivo analisar a experiência dos alunos na atividade de leitura das revistas impressa e digital, buscando compreender a eficiência dos conteúdos e os dispositivos de interação utilizados para intermediar o processo de aprendizagem. Foi possível desenvolver três análises: 1) análise dos questionários, 2) análise das avaliações de compreensão e 3) análise de vídeo. Devido a complexidade e detalhamento das análises, não será possível discuti-las nesse espaço, cabendo aqui um resumo do conjunto das análises desenvolvidas nessa pesquisa.

As análises, apresentadas na tabela a seguir, tiveram como base as categorias estabelecidas pela Teoria da Atividade de Leontiev (1978), o Sistema da Atividade de Engeström (1987), o estudo de Breakdowns e Mudanças de Foco de Bodker (1997).

\section{Tabela 2 - Conjunto das análises}

TIPOS DE ANÁLISE
1 Análise do Questionário
1.1 Perfil dos sujeitos
1.2 Contexto de ensino-aprendizagem dos sujeitos
1.3 Sistemas da Atividade de leitura das revistas digital e impressa

\section{Análise da Avaliação de Compreensão do Conteúdo}

2.1 Comparação entre as questões do Capítulo Petróleo (Revista Impressa x Revista Digital)

2.2 Comparação entre as questões do Capítulo Biodiversidade (Revista Impressa x Revista Digital)

2.3 Comparação entre os dados gerais da avaliação

\section{Análise de Vídeo}

3.1 Análise da leitura do conteúdo do capítulo

3.2 Análise do manuseio dos artefatos

3.3 Análise da orientação de manuseio e elementos de interação no tablet

3.4 Análise de Breakdowns e Mudanças Deliberadas de Foco

Fonte: autoria própria 
Assim, esta pesquisa teve como foco a análise quali-quantitativa de artefatos educacionais para uso em tablets, buscando contribuir efetivamente para o desenvolvimento de artefatos que facilitem o processo de aprendizagem dos seus usuários.

\section{RESULTADOS - DIRETRIZES PARA A ANÁLISE E DESENVOLVIMENTO DE APLICATIVOS EDUCACIONAIS PARA USO EM TABLET}

A pesquisa gerou como resultado a construção de diretrizes que foram dividas em três perspectivas: 1) conteúdo do artefato; 2) manuseio do artefato; 3) atributos físicos do artefato. Devido à limitação de páginas, neste artigo apresentaremos apenas a perspectiva do conteúdo do artefato.

\subsection{Conteúdo do artefato}

Texto - os índices gerais de leitura do conteúdo textual, obtidos através da análise dos vídeos, praticamente empataram entre os artefatos impresso (80\%) e digital (70\%). Já no índice de acertos das questões que se referiam apenas ao texto na avaliação de compreensão, a diferença se inverte, chegando a revista digital ao índice de $60 \%$ e de $56,67 \%$ a revista impressa. Embora haja uma diferença pequena, tais dados sugerem que o texto alcança um maior nível de compreensão entre aqueles que leram o conteúdo na revista digital. Assim, possivelmente, a visualização do texto ocupando quase a totalidade da tela, a possibilidade de rolar o conteúdo, são fatores que podem contribuir para o que texto na revista digital proporcione um maior conforto na leitura, facilitando assim a compreensão do conteúdo.

Infográficos - de modo geral, no Guia do Estudante, as informações do infográfico são tratadas de forma complexa e contém alguns equívocos na hierarquia das informações. Na leitura dos infográficos há uma diferença considerável entre os que utilizaram a revista impressa, chegando a $85 \%$ dos sujeitos, e os que utilizaram a revista digital, totalizando apenas $35 \%$ dos sujeitos. 0 baixo índice de leitura dos infográficos na revista digital também parece ter sido ocasionado pela dificuldade de manuseio do artefato, já que os sujeitos sequer perceberam a existência de infográficos ou dos ícones que eram links. O índice geral de acertos ficou em 45,34\% para a revista impressa e $36,67 \%$ para a revista digital. Se, para a leitura isolada do texto, o índice de compreensão foi maior entre os que leram a revista digital, o mesmo não aconteceu quando os sujeitos precisaram articular as informações contidas no texto e em infográficos. Esta constatação pode sugerir que, embora seja importante reforçar o conteúdo textual com conteúdos informacionais, nestes capítulos a presença dos infográficos e/ou seu design não contribuiu para a compreensão do conteúdo. Desta forma, sugere-se que é necessário observar os princípios do design da informação para a construção dos infográficos e também rever a contextualização entre estes e o texto.

Conteúdo Complementar - dos sujeitos que leram o conteúdo na revista impressa, 70\% fez a leitura dos itens (Resumo e Saiu na Imprensa), e dos que leram na digital, apenas $20 \%$. Na avaliação de compreensão, o índice de acerto para a pergunta sobre o item SAIU NA IMPRENSA (matéria jornalista) foi de $52 \%$ dos sujeitos na revista impressa e $26 \%$ na digital. Na revista digital há uma dificuldade de manuseio ocasionada por duas questões, aparentemente: a primeira se refere ao ícone que não informa claramente que é um link; e a segunda corresponde à localização e tamanhos 
destes ícones na tela do tablet. Assim, a localização e o tamanho do ícone SAIU NA IMPRENSA no material digital podem não ter contribuído para a percepção desta informação, levando o usuário a não visualizá-lo ou não entendê-lo como um link. Deste modo, sugere-se que haja uma maior ênfase visual nos itens que atuam como informações complementares ao conteúdo do material (Resumo, Saiu na Imprensa, entre outros).

Hipermodalidade - em comparação com os leitores do capítulo Petróleo na revista digital, houve um número maior de sujeitos (5) que acessaram os infográficos no capítulo de Biodiversidade. Como já discutido antes, esse aumento pode ter sido ocasionado pela indicação, no texto corrido do Capítulo Biodiversidade, da existência dos infográficos nos ícones laterais. Assim, ao se explicitar e reforçar a relação entre texto, infográfico e links ao longo do material pode-se facilitar a contextualização entre os conteúdos do texto e da infografia.

\section{CONSIDERAÇÕES FINAIS}

Visto que a inclusão de artefatos digitais móveis no ambiente escolar é uma realidade cada vez mais latente, o uso destes ainda apresenta obstáculos significativos para os alunos. A mudança do modelo impresso para o modelo digital envolve não só a alteração de formato e inserção de interações, mas principalmente uma nova forma de relacionar-se com a aprendizagem.

Com o objetivo de compreender esse novo cenário e encontrar respostas para a construção de artefatos digitais móveis voltados para o ensino-aprendizagem, esta pesquisa utilizou um conjunto de instrumentos metodológicos que tiveram como base o Design centro da atividade, a partir da Teoria da Atividade de Leontiev (1978), como já explorado.

A utilização da Teoria da Atividade como abordagem metodológica se mostrou bastante adequada à pesquisa, pois possibilitou observar não só as questões que envolvem o uso adequado dos artefatos, mas também apontar as possíveis falhas nos processos de aprendizagem.

Da mesma forma, ao abordar a interação humano-computador sob a ótica da Teoria da Atividade permitiu-se a expansão dos modelos habituais de análise da IHC, superando os níveis operacionais da atividade e atingindo níveis ligados às metas e motivações do uso dos dispositivos móveis.

Além disso, o uso do Sistema da Atividade de Engeström (1987) para a análise do questionário, o método de Spinillo e Hodges (2012) para a análise da avaliação de compreensão de conteúdo, e o estudo de Breakdowns e Mudanças de Foco de Bodker (1997) para a análise dos vídeos também se revelaram satisfatórios para a pesquisa.

Se por um lado as análises apresentaram evidências de uma maior facilidade de manuseio e compreensão dos conteúdos dos capítulos no artefato impresso do que no digital, por outro, os sujeitos imersos na cultura digital enxergam no modelo digital móvel um possível caminho para as demandas atuais dos processos de ensinoaprendizagem. Como já dito, nota-se um maior engajamento desses sujeitos tanto no que diz respeito ao aprendizado do manuseio da revista digital quanto ao emprego desses artefatos como mediadores processo de ensino-aprendizagem.

Por fim, esta pesquisa trouxe contribuições para o campo da aprendizagem mediada por artefatos digitais móveis, ao apontar diretrizes para análise e desenvolvimento de aplicativos educacionais para uso em tablet. Vale ressaltar que 
tais evidências não podem ser vistas isoladamente, mas sim como parte do contexto específico de ensino-aprendizagem deste estudo, apresentando-se como uma possibilidade dentre outras válidas.

\section{REFERÊNCIAS}

BARRETO CAMPELLO, Silvio. Usability for learning: a socio-cultural approach to the usability of VLEs. 2005. Tese (doutorado). The University of Reading, Department of Typography \& Graphic Comunication, GB.

BARRETO CAMPELLO, Silvio. Aprendizagem mediada por computador. In: C. Spinillo, P. Bendito, \& S. Padovani (Eds.), Selected Readings on Information Design:

communication, technology, history and education. (pp. 189-200). Curitiba: Sociedade Brasileira de Design da informação, 2009.

BATISTA, Silvia Cristina Freitas. Mobile learning: reflexões sobre o tema. Anais do 70 Congresso Integrado de Tecnologia da Informação. Trabalhos Completos. 2012.

BODKER, Susanne. A Human activity approach to user interfaces. Human-Computer Interaction, v. 4, p. 171-195, 1989.

Applying activity theory to video analysis: how to make sense of video data in human-computer interaction. In: NARDI, B. (Ed) Context and Consciousness: activity theory and human-computer interaction. Harvard: MIT Press, 1995.

ENGESTRÖM, Yrjö. Learning by expanding: an activity-theoretical approach to developmental research. 1987. 372f. Tese (doutorado) - University of Helsinki.

KAPTELININ, Victor.; NARDI, Bonnie. Activity Theory in $\mathrm{HCl}$ : Fundamentals and Reflection. Penn State's University, Penn: Morgan \& Claypool, 2012.

LEONTIEV, Alexei. Activity, consciousness, and personality. Englewood Cliffs, New Jersey: Prentice-Hall International, 1978.

O desenvolvimento do psiquismo. 2 ed. São Paulo: Centauro, 2004.

LEONTIEV, Alexei; VYGOTSKY, Levy; LURIA, Alexander. Psicologia e pedagogia: bases psicológicas da aprendizagem e do desenvolvimento. 4 ed. São Paulo: Centauro, 2012.

MOREIRA, Adelson; PEDROSA, José; PONTELO, Ivan. O conceito de atividade e suas possibilidades na interpretação de práticas educativas. Ensaio Pesquisa em Educação em Ciências, 13(3), 1-19, 2011.

MOURA, Adelina.; CARVALHO, Ana Amélia. Mobile learning: teaching and learning with mobile phones and Podcasts, 2008. Disponível em:

$<$ https://www.researchgate.net/publication/221423920_Mobile_Learning_Teaching_a nd_Learning_with_Mobile_Phones_and_Podcasts> Acesso em: 10 Jun. 2016.

TRAXLER, John. Defining, discussing, and evaluating mobile learning: the moving finger writes and having writ... The International Review of Research in Open and Distance Learning. v. 8, n. 2, 2007. 